\title{
High-dose Methotrexate/Leucovorin Regimen
}

National Cancer Institute

\section{Source}

National Cancer Institute. High-dose Methotrexate/Leucovorin Regimen. NCI Thesaurus.

Code C156264.

A regimen consisting of high-dose methotrexate and leucovorin that can potentially be used for the treatment of various central nervous system (CNS) cancers and various types of lymphoma. 